\title{
Optimization of Multiphase Technological Process Based on Simulation Modeling
}

\author{
Valentin N. Kurochkin \\ Azov-Black Sea engineering institute-branch \\ of Don state agricultural university \\ Zernograd, Rostov region, Russia
}

\begin{abstract}
An industrial experiment and simulation modeling have been conducted in order to study process optimization possibilities. Regularities of multiphase agricultural technological process functioning on the example of harvesting transport system were the object of the study. The regularities appearing during multiphase agricultural technological process functioning in agricultural organizations and their associations have been studied. The hypothesis has been proved that this system can be optimized with mathematical simulation. This optimization can result in parameter and operational system failures decrease and it efficiency increase.
\end{abstract}

Keywords - agriculture, enterprise, machine and tractor fleet, grain combine harvester, organization, planning, technological process, imitational modeling

\section{INTRODUCTION}

Nowadays agriculture of Russian Federation develops. It is a reaction to agriculture and food import decrease. The industrial growth in the agricultural sector has been about $20 \%$ for 4 years. We can state a significant "atomistic" transformation in economic relationships in the agrarian sector, aimed at the formation of numerous manufacturers of agricultural products. The conception has undergone substantial transformation for the last two decades due to the capital concentration law and business competition. Agricultural and farm enterprises have undergone consolidation, there appeared agricultural holdings, which have sustainable machine and tractor fleet. Holdings appearance is a matter of fact of manufacture integration and capital concentration [1. p. 22]. Nowadays, the main part of the crop production is produced at large scale enterprises and their alliances and holdings, which makes the issue of machine and tractor fleet utilization actual. Spice cereals cultivation prevails in Southern regions. For example, in the Rostov Region, about one and a half million ha are planted with winter wheat, other spiced cereals are planted over half-amillion ha. Harvesting process should be completed over the whole grain area in short agro technical terms; if it is irrational significant crop losses may take place. Here, the academician of RAS E. I. Lipkovich noticed: "Harvesting and storage processes are the most difficult in agricultural production. Its aim is maximal grain crops harvesting ... with simultaneous tailings gathering (TG) and soil preparation for further cropping". This calls for distinct organization of harvesterthreshers, machine-tractoraggregates, and transport utilization.
Optimization of multiphase technological harvesting and stocking processes basing on the research is good for functioning of machine utilization system and reduces grain losses during harvesting. But it is complicated without computer simulation $[2$, p. 8]. Dealing with the issue wider, we can notice that rational machine tractor fleet utilization provides steady and proper functioning of agrar multiphase technological processes. Proper consequence of these phases in productivity reduces technological gaps and parametric and functional failures of this technological system [3 p 3]. For a technological subsystem of agricultural organization providing continuity and efficiency of crops production is acute by means of machine tractor coherence according to productivity providing technical availability at the regulated level [4 p 454455]. Mathematical simulation with information technologies application is a rather innovative way of agriculture technological multiphase processes optimization.

\section{A. The aim was}

The aim was: to study possibility of multi-phase technological process optimization with simulation modeling.

\section{B. The hypothesis}

The hypothesis is rational organization of machine tractor fleet multiphase technological utilization during crop harvesting with mathematical simulation decreases parameter and functional failures and increases efficiency.

\section{The object of the study}

The object of the study is regularities of multi-phase agrarian technological process functioning on the example of harvesting transport system.

\section{The subject of the study}

The subject of the study is dependencies and regularities appearing at machine-tractor fleet utilization in agricultural organizations and their alliances.

According to the object of the study multiphase production processes in big agricultural organizations has been studied in order to determine efficiency factors and developing measures for decreasing parameter and functional failures of the machine-tractor fleet exploitation. Studies have been conducted on the example of harvesting - transport process for 
determining factors of its efficiency increase and developing measures for decreasing parameter and functional failures.

Harvesting and storing works, conditions and utilization of machine- tractor fleet by agriculture organizations are studied by E. I. Lipkovich, M.S. Runcheev, V.I. Chernoivanova, A.E. Severnogo and others. Studying organization with Markov processes theory and its applications was done by doctors of sciences N. I. Agafonov, Yu. A. Tsarevym, A. I. Burianov and others.

\section{Methods And Results}

After the text edit has been completed, the paper is ready for the template. Duplicate the template file by using the Save As command, and use the naming convention prescribed by your conference for the name of your paper. In this newly created file, highlight all of the contents and import your prepared text file. You are now ready to style your paper; use the scroll down window on the left of the MS Word Formatting toolbar.

Nowadays mathematical simulation is widely used for solving engineering problems. For example, such scientists as Elaheh Maleki, Farouk Belkadiend and AlainBernard have developed a meta-model for the service and product system based on the engineering type of system [5 p 39-44]. Mathematical simulation has been used for studying and researching agrarian problems in the sphere of technical service [6, pp. 742-751], in particular, creating means of technical service [7 p 3807-3815]. From the methodological point of view, the work of Atakan Sünnetcioglu and Rainer Stark is interesting, where they study transitive relations for generating consequent traceability in engineering systems with simulation models [8 p 311-318]. The technological process in our case can be introduced as transactions service, moving through standing crop processing phase sequence.

The most suitable simulation method of transaction service is general process simulation system (GPSS) of Michigan University [9 p 24-27]. Ito apply this method representation possibility of transactions service as Markov's process has been studied and determined that mathematical simulation as Markov's process allows optimizing computer simulation of the technological process. To fulfill this approach it is necessary to identify transaction input flows. Identification was done by well-known experiments methods. [10 p 260276]. The experiment was conducted in the field studies. As the result of the experiment the transaction flows regularities have been determined, duration distribution laws of their phase service, occasional transaction flows characteristics and their service mechanism (Table 1).

Regularities of the technological system operational phases have been determined, parametric failure indexes formation, including maintenance queuing. Basing on these assumptions and experiment results simulation modeling with GPSS system is possible during formalized scheme development as well as a mathematical model and modeling algorithm development.
TABLE I. TECHNOLOGICAL SYSTEM CHARACTERISTIC VALUES BY OPERATIONS

\begin{tabular}{|c|c|c|c|c|}
\hline \multirow[t]{2}{*}{ Phase } & \multirow{2}{*}{$\begin{array}{c}\text { Phase } \\
\text { № }\end{array}$} & \multicolumn{2}{|c|}{ Loading coefficient, $\%$} & \multirow{2}{*}{$\begin{array}{l}\text { Queuing, } \\
\text { Hour }\end{array}$} \\
\hline & & value & inaccuracy & \\
\hline Swathing & 1 & 98 & 102 & 3.6 \\
\hline combine harvesting & 2 & 80 & 102 & 0.6 \\
\hline $\begin{array}{l}\text { with tailors blending/ } \\
\text { without blending }\end{array}$ & 3 & 68 & 150 & 2.2 \\
\hline Grain pile gathering & 4 & 37 & 270 & 0.7 \\
\hline grain: transportation & 5 & 97 & 104 & 2.2 \\
\hline Primary cleaning off & 6 & 93 & 107 & 1.7 \\
\hline $\begin{array}{l}\text { Secondary cleaning } \\
\text { off }\end{array}$ & 7 & 93 & 107 & 10.4 \\
\hline $\begin{array}{ll}\text { Loading } & \text { and } \\
\text { transportation } & \end{array}$ & 8 & 45 & 222 & 0.2 \\
\hline $\begin{array}{l}\text { Weighing and } \\
\text { unloading }\end{array}$ & 9 & 5196 & 196 & 0.1 \\
\hline Tailors gathering & 10 & 88 & 115 & 1.4 \\
\hline Primary tillage & 11 & 94 & 106 & 2.7 \\
\hline beardless plowing & 12 & 93 & 108 & 1.1 \\
\hline moldboard plowing & 13 & 87 & 115 & 1.1 \\
\hline $\begin{array}{l}\text { Blended tailoring } \\
\text { transportation }\end{array}$ & 14 & 99 & 102 & 1.9 \\
\hline Stacking & 15 & 88 & 113 & 0.6 \\
\hline Pile transportation & 16 & 31 & 323 & 0.1 \\
\hline Pile thrashing & 17 & 27 & 441 & 0.03 \\
\hline $\begin{array}{l}\text { Swath thrashing with } \\
\text { tailors blending }\end{array}$ & 18 & 94 & 107 & 10.3 \\
\hline $\begin{array}{lr}\text { Swath } & \text { thrashing } \\
\text { without } & \text { tailors } \\
\text { blending } & \\
\end{array}$ & 19 & 19 & 130 & 0.3 \\
\hline
\end{tabular}

\section{A. Formal description}

Formal description of the harvesting-transport technological system: Let: $z$-harvesting system state is described by the set of objects $\boldsymbol{z}_{1, z_{2}}, \ldots \quad z_{n}$, where $z_{i} \in Z_{i}, i=1,2, . ., n$, where $Z i$ are predetermined values. Usually the researchers [10] consider direct product:

$$
\hat{Z}=Z_{1} \times Z_{2} \times \ldots \times Z_{n}
$$

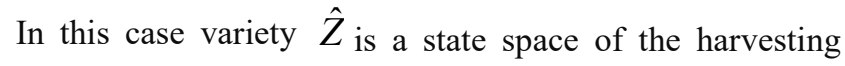
process, which is the value of all ordered sets $z_{1}, z_{2}, \ldots, z_{n}$ including those not belonging to the state of the harvesting process under study, for which all system states are characterized by variety of interval points $Z_{1}-\left(0, z_{1}^{0}\right)$ on axes $O Z_{1}, Z_{2}$ is interval points variety $\left(0, z_{2}^{0}\right)$ on axis $0 Z_{2}$. and so on by the analogy. The input data are transactions $x \in X$, where $X$ is system input set, with the transaction entering the system at the moment $t \in T$, is denoted $x(t)$. Input and output signals in this case are transactions maintained in the process phases. Let: for a period of time $\Delta \mathrm{t}_{\mathrm{i}} \mathrm{B}$ a part of the crop field $d x$ is treated, than they make a transaction together for the given time: 


$$
\rho=\int_{t_{1}}^{t_{2}} f\left(t, \eta_{i}\right) d t
$$

In this case the system input $x$ is described $x_{i} \in X_{i}=1,2, \ldots, m$, where $X i$ are prescribed values. Transaction plurality is determined by input data variety $x=L(t)$, corresponding to harvesting system operation conditions. The last also generates maintained transactions, which for $y \in Y$ at $t \in T$ are determined as $y(t)$ Then the output data variety of "maintained" system transactions will be $[10]$

$$
\hat{Y}=Y_{1} \times Y_{2} \times \ldots \times Y_{r}
$$

Summarizing the idea of this system, following some researchers we will suppose that the system state $\mathrm{z}(\mathrm{t})$ for moments $t \in T$ a so that $t \geq t_{0}$ is determined by system transition operator [4]

$$
t \in T z(t)=H\left\{t, t_{0}, z\left(t_{0}\right),\left(t, x_{L}\right]_{t_{0}}^{t}\right\}
$$

The operator fulfills the developed algorithm. In this case research methodology of complex systems starts with its formalization which requires input parameters identification and control inputs, where $g \in \Gamma, \hat{\Gamma}=\Gamma_{1} \times \Gamma_{2} \times \ldots \times \Gamma_{m}$ ).

Input and control actions were space points $\bar{X}=X \times \Gamma$, of summarized input parameters $\left.\bar{x}=(x, g)=x_{1}, x_{2}, \ldots, x_{n}, g_{1}, g_{2}, \ldots g_{m}\right)$. When transactions and system state control actions are input into the system, if there is a Markov's process, they depend on $\left(t, x_{L}\right)_{T}$ and $\left(t, g_{M}\right)_{T}$. With the account of this situation transaction operator becomes $z(t)=H\left\{t, t_{0}, z\left(t_{0}\right),\left(t, x_{L}, g_{M}\right]_{t_{0}}^{t}\right\}$.

\section{B. Fullfillment}

Harvesting system operation simulation with the software received experimentally in effective enterprises allowed receiving the following result of mathematical simulation (Fig. 1)

Load coefficient changes according to process phases

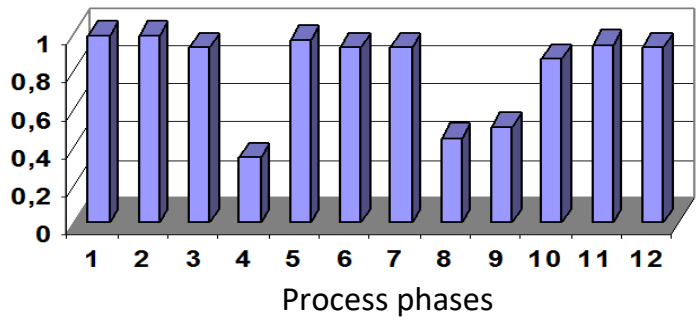

Fig. 1. Load changes in multi phase process machines
The graph shows "narrow" phases when transactions form queues. Increasing their productivity decreases queues; consequently, eliminate parametric failures, increase passing through capability of the harvesting technological system and increase its efficiency.

\section{CONCLUSION}

.As the result of studying multiphase systems with simulation modeling method it has been determined that idle hours phases coefficient is greater where there are two and more transaction flows are consolidated, and a greater value of the coefficient is at the phase numbers 1,3,5, 7 (and other prime numbers); it is possible that in other branches technological systems do not possess these features.

Prime numbers phenomenon is explained by that transaction consolidation decreases the interval between their input, that is why the flow approaches to Weibull's one. Computer testing showed the property: even number of phase service posts increases system efficiency and decreases parameters and functional failures.

Thus, it has been proved that rational organization of multiphase technological system of machine tractor fleet utilization during crop harvesting based on mathematical simulation decreases parameter and operational failures and increases its efficiency.

\section{References}

[1] V.N. Kurochkin, "Strategic development management of vertically integrated structures of the regional cluster: monography", Zernograd: Azov-Black Sea engineering institution FSBEE HE Donskoi SAU, 2017, p. 193

[2] E.I. Lipkovich, V.N. Kurochkin, R.E. Stein, Yu.A. Timofeev, L.M Sergeeva, L. D. Pasechnaya, Harvesting transport and storage process in regional agrarian complex: organization bases and mathematical simulation: monography, RAS E. I. Lipkovich Eds, Moscow: AUAAS, 1987, p.144.

[3] Techniques reliability. Technological systems. Terms and definitions: GOST 27.004- 85, Moscow: Standards publishing house, 1986, p.60, Retrieved from: https://standartgost.ru/g/\%D0\%93\%D0\%9E\%D0\%A1\%D0\%A2_27.004 -85 .

[4] V.N. Kurochkin, Efficiency and reliability of complex organizational system operation, Rostov-on-Don: Rostizdat, 2010, p.494.

[5] E. Maleki, F. Belkadi, A. Bernard, "Meta-model for Product-Service System based on Systems Engineering approach", Procedia CIRP, vol. 73, 2018, pp. 39-44

[6] V.N. Kurochkin, A.A. Seryogin, N.V. Valuev, V.P. Zabrodin, V.S Gazalov, S.L. Nikitchenko, "Mathematical modeling of agricultural machinery technical maintenance", Journal of fundamental and applied sciences, vol. 9, no. 7S, 2017. pp. 742-751

[7] A. A. Seregin, S. L. Nikitchenko, V. N. Kurochkin, N. V. Valuev and S. V. Smykov, Hinged aggregate for technical maintenance of machines: Modeling, testing and conditions of application, Journal of Mechanical Science and Technology, vol. 32 (8), 2018, pp. 3807-3815, DOI 10.1007/s12206-018-0733-4

[8] A. Sünnetcioglu, R. Stark, "Using Transitive Relations for Automatic Creation of Consistent Traceability in Model-based Systems Engineering", Procedia Manufacturing, vol. 24, 2018, pp. 311-318.

[9] T.G. Shriber, GPSS simulation: translated from English, Moscow: Machine Building, 1980, p.592.

[10] N.P. Buslenko, V.V. Kalashnikov, N.I. Kovalenko, "Lectures on complex system theory", Moscow: Soviet Radio, 1973, p. 460. 